\title{
Assessment of the Lebanese grapevine germplasm reveals a substantial diversity and a high potential for selection
}

\author{
Lamis Chalak $^{1}$, Said Touma ${ }^{2}$, Stephanie Rahme ${ }^{1}$, Rani Azzi ${ }^{3}$, Fabrice Guiberteau ${ }^{3}$, and Joe-Assaad Touma ${ }^{2}$ \\ ${ }^{1}$ Faculty of Agricultural Sciences, The Lebanese University, Dekwane, Beirut, Lebanon \\ ${ }^{2}$ Château St Thomas, Kab-Elias, Bekaa, Lebanon \\ ${ }^{3}$ Château Kefraya, Kefraya, West Bekaa, Lebanon
}

\begin{abstract}
Lebanon is illustrious for the cultivation of grapevine since the old antiquity. Grapevine is well adapted to the agroclimatic conditions of the country which makes it one of the major element of the Lebanese agriculture. Nevertheless germplasm assessment has attributed limited interest to grapevine while genetic resources have not been exploited before despite their potential in adaptation to environmental changes. In this study we assess the diversity of traditional grapevine accessions growing in different production areas in Lebanon. A total of 35 accessions belonging to 22 vernacular names were evaluated using 33 leaf and fruit traits previously developed by OIV. An important variability was revealed among the accessions studied based on grape and grain characteristics. The most discriminant traits were grape and grain weight, dimensions, form, and skin color; leaf size, form, color, lobes number, depth of petiole sinus. Hierarchical clustering analysis showed five main clusters, each regrouping accessions of different named varieties and different agro-climatic areas. An intra-varietal variability is also suspected. Although preliminary, our results indicate a potential of genetic diversity within the Lebanese grape germplasm that should be further investigated in order to understand their performance and to evaluate them in selection programs.
\end{abstract}

\section{Introduction}

Lebanon is one of the first countries worldwide to have implemented vineyards which gradually became a traditional culture in this country for the production of both table grapes and wine [1]. Today viticulture occupies the eighth rank in the agricultural sector in the country, with a production area of 9,240 hectares and an annual production of about 89000 tons of table grapes [2,3] versus 3000 hectares and approximately 10000 tones for wine grapes $[3,4]$. In addition about 800 hectares of vineyards are intended for the production of Lebanese Arak [3].

Commercial plantations of table grapes have long been made up of four local varieties, commonly known as Tfeifihi, Beitamouni, Maghdouchi and Obeidi. More recently, the new plantations are mostly constituted of improved varieties imported from Europe and the United States. As to Arak production, it is mostly relying on Obeidi variety produced by commercial plantations and more secondarily on the the variety called Merwah produced at a family level. For wine grapes, Lebanese vineyards are almost exclusively occupied by noble hybrid varieties introduced from Europe and USA. It was until 2012-2013 that the local variety Obeidi is successfully used in the wine industry by Chateau Saint Thomas [5].

The long history of viticulture in Lebanon suggests the existence of a large indigenous germplasm associated to a wide range of traditional varieties that are well adapted to the various agro-climatic conditions of the country. However the genetic resources of grapevine in Lebanon were rarely addressed. About fifty local varieties of table grapes are still cultivated across the country [6].
Nevertheless, this traditional germplasm is threatened by various anthropogenic pressures and more particularly the progressive replacement of local varieties by more advantageous improved varieties imported from abroad [6]. Moreover, the growing territorial reorganization in rural areas may completely wife off old vines entire vineyards which constitute a significant part of the genetic resources of vines even before they are studied or duplicated in a new location. Conscientious of the importance of preserving the genetic resources of the vine, the Lebanese Agricultural Research Institute established in 1998 a national collection containing 71 local accessions of table grapes belonging to 52 vernacular names [7].

However to date, with the exception of the variety Obeidi, the Lebanese vine germplasm has not been evaluated for its potential in the fermentation process. But today with the global trend to return to local plant genetic resources for their better tolerance to biotic and abiotic stresses [8], it would be necessary to evaluate and develop the Lebanese traditional varieties of vines for fermentation and wine production. In this context, a collaborative action involving the Lebanese University with Château Saint Thomas and Château Kefraya (both located in western Bekaa), has been recently undertaken for the evaluation of the local grapevine germplasm with the perspective of conservation and valorization in winemaking process. The present work aims to: 1) explore and collect traditional indigenous varieties (here called accessions) across the country and which have a potential interest in winemaking (berries sensory test); and 2) characterize these accessions using a set of morphological descriptors of the leaf, the grape cluster and the berries. 


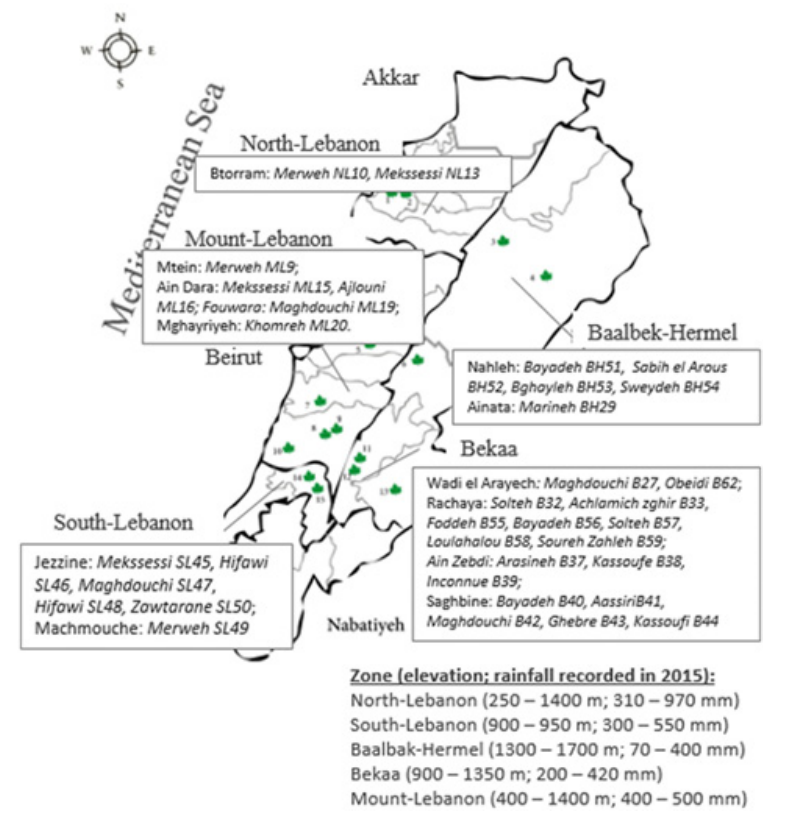

Figure 1. Geographic distribution of the 35 Lebanese vine accessions studied.

\section{Materials and methods}

\subsection{Plant Material}

Field surveys were performed during vegetation and production (June-September) in 2015 with the aim of collecting the in situ indigenous grapevine germplasm growing throughout in family gardens and commercial plantations throughout Lebanon. Thirty two locations have been retained for the study spread over four main geographical areas, the North, the South, Mount Lebanon, and the elevated agricultural plateau of Bekaa (Fig. 1). They were located between 250 and $1700 \mathrm{~m}$ a.s.l. and receiving rainfalls of 200 to $1050 \mathrm{~mm}$. A total of 35 accessions were defined for the study, based on the berry sensorial test retaining only the ones with soft, juicy and flavored berries. For each accession, one vine of 15 to 25 years old and having good and health development was chosen to be submitted to morphological characterization. In order to assure data traceability, information on GPS coordinates and elevations of the sampled trees were collected (data not shown).

\subsection{Morphological descriptors}

Characterization of grapevine accessions was based on the list descriptors which were previously developed by the International Organization of Vine and Wine [9]. For each accession, 26 qualitative and seven quantitative descriptors of the leaf, the grape bunch and the berry were examined. They are: leaf shape, color and size, vein pigmentation on both upper and lower sides of the leaf, blade profile and embossment, teeth form and length, sinus form, opening and teeth, depth of the petiolar sinus with respect to veins, hair density on the upper and lower sides of the leaf, pedicel length and pilosity; grape bunch shape, consistency, size and weight; berry shape, length, width, weight, skin and pulp color, succulence, firmness, flavor, berry detachment from pedicel and pedicel length.

\subsection{Data analysis}

Qualitative characteristics have been described and scored. For quantitative traits, the mean \pm standard deviation and coefficient of variation were calculated. To assess the degree of similarity between the units tested and understand the relationships between them, the data were subjected to a principal component analysis (PCA) in order to condense the quantitative and qualitative traits in a small number of synthetic components. Thus, the degree of contribution of each of the characters to the total variation was calculated in order to indicate the most relevant characters [10]. Hierarchical Cluster Analysis was executed using Euclidean Distance following the ward's method [11].

\section{Results}

\subsection{General status of collected accessions}

The surveyed accessions were mostly growing in small scale to large commercial plantations of 0.2 to 2 ha located in the high plateau of Bekaa, Shouf (Mount Lebanon), Batroun (North Lebanon), Hasbaya (South Lebanon) and Sour (South Lebanon) (Fig. 1). Ten accessions came from kitchen gardens located in Mtein (Mount Lebanon), Btorram (North Lebanon), Ain zebde (Bekaa), Ainata (Baalbek-Hermel) and Jezzine (South Lebanon). Four accessions were taken from houses backyards in the villages of Fouwara (Mount Lebanon), Ain dara (Mount Lebanon), and Wadi el Arayech (Bekaa). One accession of more than 150 years was found in a Maronite convent in Bsarma village (North Lebanon), elevated on a horizontal trellis, receiving the thorough care of the monks. The last six accessions, aged more than 100 years, were found abandoned, surviving on their own in forsaken lands in Nahleh village (Baalbek-Hermel) and Machmouchi village (South Lebanon). Many of them were rather growing in very harsh conditions and in marginalized and rocky lands.

Cultural practices are applied in the commercial plantations and kitchen gardens, using furrow irrigation, mineral and organic fertilization. Pruning is practiced as well, leaving around 10 buds on one year shoots. Vines are generally grown on trellis of $1.8 \mathrm{~m}$ average height for commercial plantations and $3 \mathrm{~m}$ height for kitchen gardens. In small scale commercial vineyards, vines are grown on the ground without any support other than a wood stick holding them about $1 \mathrm{~m}$ above the soil surface to protect them from snow damages, with a culture density between 80 and 160 stalk per dunum.

Twenty two putative names were inventoried for the 35 accessions studied (Table 1): Aassiri (one accession), Achlamich zghir (one accession), Ajlouni (one accession), Arasineh (one accession), Bghayleh (one accession), Bayadeh (three accessions), Foddeh (one accession), Ghebre (one accession), Hifawi (two accessions), Kassoufe (two accessions), Khomre (one accession), Loulahalou (one accession), Maghdouchi (five accessions), Marineh (one accession), Mekssessi (two accessions), Merweh (three accessions), Obeidi (one accession), Sabih el Aarous (one accession), Solte (two accessions), Soure Zahle (one accession), Sweydeh (one accession), Zawtarne (one accession) and one last unknown accession. As to farmers cognitive informaton, many of the sampled accessions were said to be 
indegneous and given putative names in Arabic language often in association with a trait of the fruit such as Khmore (meaning red wine color) or the geographic area e.g. Maghdouchi (as to the name of the village of origin).

\subsection{Leaf characteristics}

Leaf shape varied widely between the studied accessions (Table 1). Nine accessions present wedge-shaped leaves (e.g. Solteh B57, Hifawi SL48), eleven have pentagonal leaves (e.g. Maghdouchi ML19, Mekssessi SL45) and thirteen have orbicular leaves (e.g. Merweh NL10, Bayadeh B56). The majority of the accessions have leaves with five lobes and a U-shaped petiole sinus not limited by ridges, except Achlamich zghir B33 having leaves of three lobes with a brace opening sinus. Most of the accessions have an open sinus, whereas the others have overlapping to slightly overlapping sinuses. All accessions showed no embossment at the leaf blade. Twenty-seven accessions have a pedicel shorter than the median vein, four are characterized by a pedicel longer than the median vein and three have the pedicel and the median vein of the same length. As for the leaves teeth, sixteen accessions have straight teeth (e.g. Arasineh B37, B44 Kassoufi), while twelve others have convex teeth (e.g. Maghdouchi ML19, Marineh BH29). The five remaining accessions are distinguished by teeth rectilinear on one side and convex on the other side (e.g. Aassiri B41, Maghdouchi SL47). These teeth are long for only three accessions, and short to medium for most accessions studied. A high hairiness on both sides of the leaf and on the pedicel is noted particularly for Marineh BH29 while accessions Soureh Zahleh B59 and Loulahalou B58 are completely glabrous (Table 1).

\subsection{Grape cluster characteristics}

The majority of the accessions present funnel clusters (e.g. Obeidi B62, Mekssessi ML15) while in other accessions the cluster shape varies between conical (e.g. Marineh BH29, Bghayleh BH53) and cylindrical (e.g. Khomreh ML20, Sabih el Arous B52) (Table 1; Fig. 2). As to clusters consistency most accessions show a medium consistency, while Zawtarane SL50 ranks among the accessions with the most compact clusters and Khomreh ML20 among the accessions with the loosest clusters. Regarding the weight, the heaviest clusters are found in Zawtarane SL50 with an average of $1233 \mathrm{~g}$ and the lightest clusters in Merweh NL1O with an average of $135 \mathrm{~g}$. Cluster size varies between 20 and $40 \mathrm{~cm}$ in most accessions with Loulahalou B58 having the longest clusters $(40 \mathrm{~cm})$. When examining the coefficients of variation, we notice that cluster weight varies much more $(\mathrm{CV}=6.53)$ than its size $(\mathrm{CV}=0.17)$ (data not shown).

\subsection{Grape berries characteristics}

Berries external appearance presents an important variability among the accessions studied (Table 1). Berries shape varies between spherical (e.g. Merweh ML9, ML15 Mekssessi), long elliptical (e.g. Zawtarane SL50, Maghdouchi B42) and short elliptical (e.g. Arasineh B37, Solteh B32). Skin color appears yellow-green for 31 accessions (e.g. Hifawi SL46, Ajlouni ML6), red for

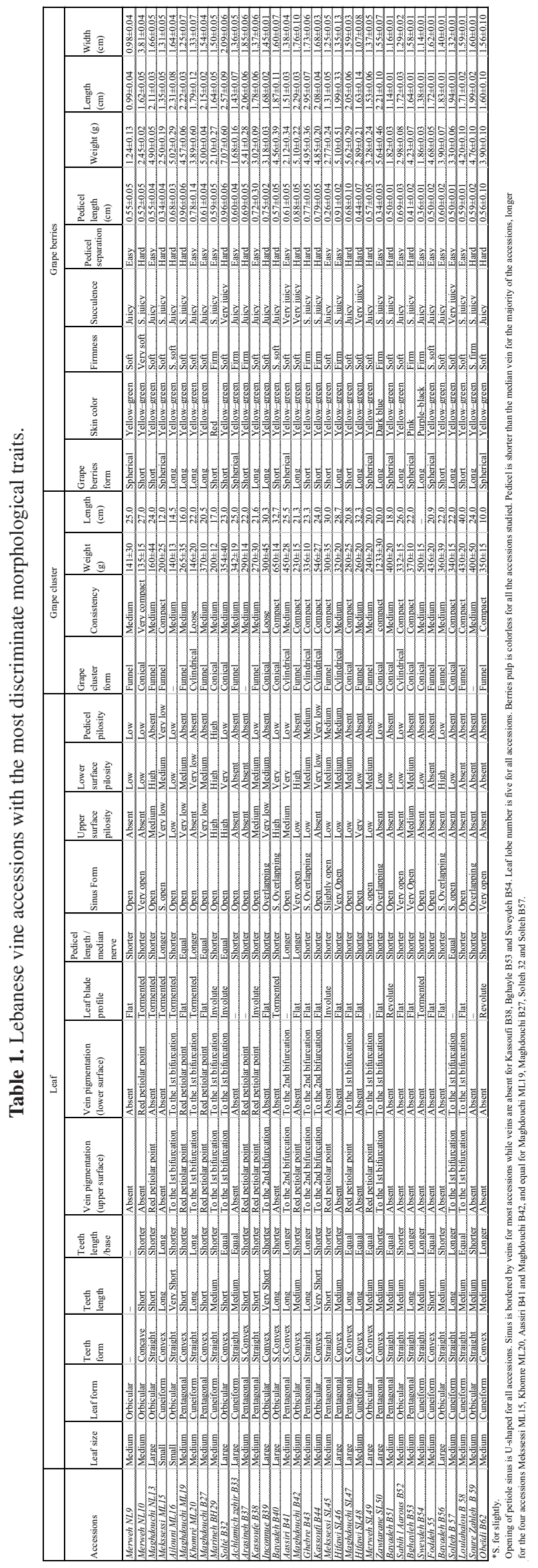




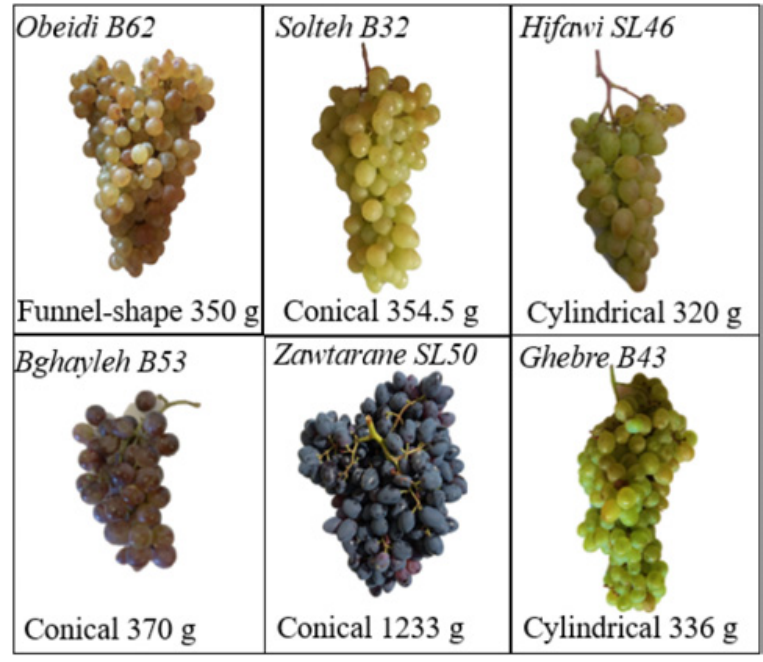

Figure 2. Diversity of grape cluster characteristics among the 35 Lebanese vine accessions.

Marineh BH29, dark blue for Zawtarane SL50, purpleblack for Sweydeh B54 and pink for Bghayleh B53, while the pulp is colorless for all the evaluated accessions. As to berries dimensions, Solteh B32 and Ghebre B43 have the longest berries with $2.57 \mathrm{~cm}$ and $2.95 \mathrm{~cm}$ respectively, while the largest ones are found for Solteh B32 and Zawtarane SL50 with $7.07 \mathrm{~g}$ and $5.64 \mathrm{~g}$ respectively. Merweh ML9 has the smallest berries with $1.24 \mathrm{~g}$ weight, $0.9 \mathrm{~cm}$ length and $0.98 \mathrm{~cm}$ width. When comparing the coefficients of variation, we notice that the weight of the berry $(\mathrm{CV}=0.40)$ varies much more than its length $(\mathrm{CV}=0.22)$ and width $(\mathrm{CV}=0.31)$ (data not shown).

\subsection{Principal components analysis}

A principal component analysis involving 31 morphological characters was performed to identify the most discriminating characteristics (Table 2). The first four components present $45 \%$ of the total variation. The first component is characterized by a percentage of variation of $17 \%$ and is mainly represented by the length and width of the berries, the color and shape of the leaf and the length of the pedicel. The second component explains $10 \%$ of the total variation and includes principally the size, weight and shape of the cluster, and the bottom of petiole sinus. The third component, characterized by a percentage of $9 \%$, is dominated by the consistency and shape of the cluster. The fourth component marked by $8 \%$ of the total variation is defined by the shape and the length of the leaf teeth, as well as the length of the teeth compared to the median vein and the presence of hair on the pedicel. These 14 descriptors are probably the most relevant ones to explain the variability within the studied accessions.

\subsection{Relationships among accessions}

The hierarchical clustering analysis based on the traits studied allowed to classify the 35 accessions into five groups at a similarity distance of 0.6 (Fig. 3).

The first group (G1) consists of eight accessions collected from Mount Lebanon and Bekaa with the majority of clusters presenting a funnel shape and elliptical soft berries. This group can be divided into two subgroups at a distance of 0.5: G1.1 includes
Table 2. Principal component analysis of the different characteristics evaluated for the Lebanese olive centennials.

\begin{tabular}{|l|c|c|c|c|}
\hline Characteristics & Fact 1 & Fact 2 & Fact 3 & Fact 4 \\
\hline Cluster weight & $\mathbf{0 . 0 1}$ & $\mathbf{- 0 . 3}$ & $\mathbf{0 . 2 7}$ & $-\mathbf{0 . 1 9}$ \\
\hline Cluster Length & $\mathbf{- 0 . 0 7}$ & $\mathbf{- 0 . 3 2}$ & 0.02 & 0.07 \\
\hline Cluster Form & $\mathbf{0 . 1 3}$ & $\mathbf{- 0 . 2 5}$ & $\mathbf{- 0 . 2 8}$ & -0.21 \\
\hline Cluster consistency & $\mathbf{- 0 . 0 3}$ & -0.04 & $\mathbf{0 . 3 6}$ & -0.14 \\
\hline Separation of the pedicel & $\mathbf{- 0 . 0 8}$ & -0.21 & 0.19 & -0.02 \\
\hline Berries form & $\mathbf{- 0 . 0 3}$ & 0.12 & 0.09 & 0.16 \\
\hline Berries color & $\mathbf{- 0 . 0 3}$ & 0.31 & $\mathbf{0 . 2}$ & -0.01 \\
\hline Succulence & $\mathbf{0 . 0 3}$ & -0.09 & $\mathbf{- 0 . 2 1}$ & 0.22 \\
\hline Firmness & $\mathbf{- 0 . 0 7}$ & 0.24 & $\mathbf{0 . 2 7}$ & -0.03 \\
\hline Pedicel length & $\mathbf{- 0 . 2 6}$ & -0.06 & -0.1 & -0.04 \\
\hline Berries weight & $\mathbf{- 0 . 2 4}$ & -0.06 & 0.08 & 0.08 \\
\hline Berries length & $\mathbf{- 0 . 3 4}$ & -0.01 & 0.04 & 0.12 \\
\hline Berries width & $\mathbf{- 0 . 2 6}$ & -0.01 & 0.04 & -0.07 \\
\hline Lobes number & $\mathbf{- 0 . 2 5}$ & 0.13 & -0.15 & 0.06 \\
\hline Leaf size & $\mathbf{- 0 . 2 5}$ & -0.02 & -0.14 & 0.04 \\
\hline Leaf form & $\mathbf{- 0 . 2 7}$ & -0.12 & -0.07 & -0.11 \\
\hline Leaf color & $\mathbf{- 0 . 2 7}$ & -0.16 & 0.11 & -0.04 \\
\hline Teeth form & $\mathbf{0}$ & -0.08 & 0 & $\mathbf{0 . 3 9}$ \\
\hline Teeth length & $\mathbf{0 . 0 5}$ & -0.13 & 0.11 & $\mathbf{0 . 3 5}$ \\
\hline $\begin{array}{l}\text { Teeth length compared } \\
\text { to their base }\end{array}$ & $\mathbf{0 . 0 6}$ & -0.14 & -0.02 & $\mathbf{0 . 3 1}$ \\
\hline $\begin{array}{l}\text { Nerves pigmentation } \\
\text { (upper surface) }\end{array}$ & $\mathbf{- 0 . 2 6}$ & -0.04 & 0.06 & 0.11 \\
\hline $\begin{array}{l}\text { Nerves pigmentation } \\
\text { (lower surface) }\end{array}$ & $\mathbf{- 0 . 2 3}$ & -0.05 & 0.12 & 0.12 \\
\hline Embossment of the limb & $\mathbf{- 0 . 0 3}$ & 0.04 & -0.07 & 0.21 \\
\hline Leaf profile & $\mathbf{- 0 . 0 3}$ & 0.04 & -0.02 & -0.21 \\
\hline $\begin{array}{l}\text { Pedicel length compared } \\
\text { to median vein }\end{array}$ & $\mathbf{- 0 . 1 1}$ & -0.11 & -0.04 & 0.15 \\
\hline Petiole sinus form & $\mathbf{- 0 . 2}$ & -0.01 & 0.08 & 0.13 \\
\hline Petiole sinus borders & $\mathbf{- 0 . 2 2}$ & 0.16 & $-\mathbf{0 . 2}$ & -0.18 \\
\hline Petiole sinus bottom & $\mathbf{- 0 . 0 3}$ & $\mathbf{0 . 2 6}$ & -0.07 & 0.04 \\
\hline $\begin{array}{l}\text { Hair density on the } \\
\text { upper surface }\end{array}$ & $\mathbf{- 0 . 2 1}$ & 0 & -0.17 & -0.16 \\
\hline $\begin{array}{l}\text { Hair density on the } \\
\text { lower surface }\end{array}$ & $\mathbf{- 0 . 2 4}$ & -0.07 & -0.22 & -0.08 \\
\hline Hair density on the pedicel & $\mathbf{- 0 . 1 9}$ & 0.18 & -0.03 & $-\mathbf{0 . 2 5}$ \\
\hline Variance & 0.02 & 0.02 & 0.03 \\
\hline
\end{tabular}

Maghdouchi ML19 and Mekssessi ML15; G1.2 consists of Obeidi B62, B33 Achlamich, Solte B32, Ghebre B43, Maghdouchi B42, Maghdouchi B27. This subgroup is particularly homogeneous, grouping six accessions of different common names, all from the Bekaa and with a significant similarity.

The second group (G2) consists of four accessions Khomre ML20, Ajlouni ML16, Zawtarane SL50 and Merweh ML9, growing in Mount and South Lebanon. These accessions have large clusters (150-1233 g) and large berries (1.3-5.64 g) of white color, except Zawtarane SL50 that has large blue berries.

The third group (G3) consists of only two accessions collected from the Bekaa: Kassoufi B44 and Bayadeh B40, with compact clusters, short elliptical berries and orbicular leaves.

The fourth group (G4) consists of eight accessions that have elliptical berries, out of which three have red skin: Bghayleh B53, Sweydeh B54 and Marineh BH29. These eight accessions come from Baalbek Hermel, Bekaa and South Lebanon. 


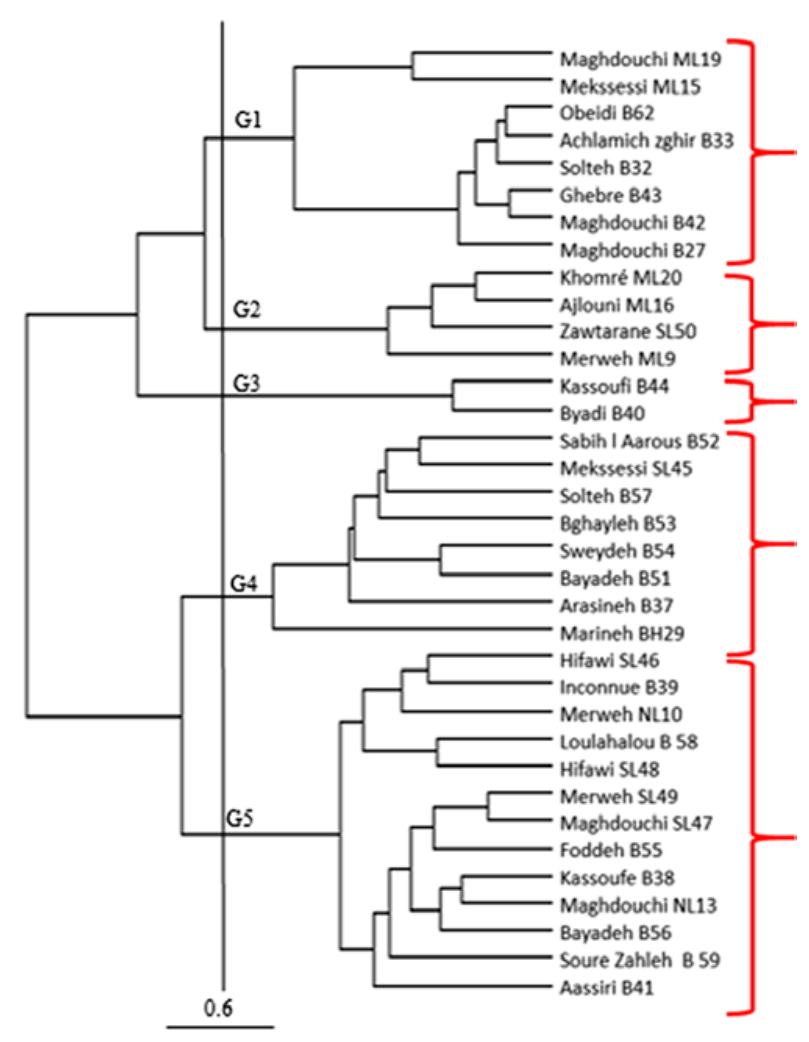

Figure 3. Relationships among 35 Lebanese vine accessions based on Jaccard distance and UPGMA clustering.

The fifth group (G5) is the largest and most diversified one. It consists of 13 accessions carrying nine vernacular names and growing in the Bekaa, North and South Lebanon. These accessions have clusters longer than $20 \mathrm{~cm}$ with white, spherical and elliptical berries, and pentagonal leaves. This group can be divided, at a short distance of 0.4 in two subgroups, each comprising accessions from different areas of the country but sharing strong similarity.

Some accessions with the same local vernacular names but growing in different locations and are differently classified in the dendrogram. This was noted for the accessions of Maghdouchi, Merweh, Solteh, Bayadeh. For example Maghdouchi ML19 (Fouwara-Shouf) and Maghdouchi B27 (Wadi el-Arayesh Zahle) are found in the first group, while Maghdouchi SL47 (Jezzine) and Maghdouchi NL13 (Btorram, Koura) are in the fifth group. This distribution of accessions supposed to belong to the same variety in different groups is probably due to differences in agro-climatic conditions and cultural practices that normally influence the morphological characteristics. Intra-varietal variability is not excluded but cannot be discussed without the genetically analysis.

\section{Discussion}

Morphological characterization of any cultivated species is the first indicator of variability and a powerful tool for its valorization and subsequent conservation in a specific collection [12]. For grapevine, ampelography is the science of identification and description of grape varieties [13]. The characters of the leaves certainly takes the first place in ampelography. As for the cluster, it arouses the interest of ampelographers and are of immense commercial importance [14].
In this study 35 indigenous accessions with 22 common names were studied, of which only four accessions are of colored berries (red-blue-pink blackblack purple). This small percentage $(11 \%)$ of red accessions is probably the result of the great trend of Lebanese farmers to grow white grapes for the production of Arak. The study revealed significant morphological variability between indigenous grape varieties, including cluster and berries dimensions, weight, consistency and shape. Indeed, these criteria were the most discriminating between the characters studied. These results confirm those previously reported on the Lebanese germplasm of table grapes which also described tremendous morphological diversity $[6,15]$.

Moreover, our study has identified for the first time nine new vernacular names that have not been mentioned or quoted in previous studies [15] and not part of the national collection of LARI [7]. They are: Ajlouni, Bghayleh, Foddeh, Ghebre, Khomre, Marineh, Solteh, Sabih el Aarous and Zawtarane. This confirms the fact that Lebanon is a reservoir of vine genetic resources and it will be imperative to address a special attention to the characterization, valorization and preservation of this heritage.

In considering the origin of the accessions studied, 17 vernacular names of the 22 initially studied (73\%) come from the plateau of Bekaa, of which 10 were found exclusively in this region. They are Solteh, Arasineh, Aassiri, Ghebre, Fodeh, Loulahalou, Soure Zahleh, Sabih el Aarous, Bghayleh andMarineh. Indeed the Bekaa has been always recognized since ever as the main area of viticulture, and thereby hosts the greatest diversity of endogenous varieties. This specificity is also found in the casa of Jezzine where the accessions called Zawtarane and Hifawi were found and were not spotted anywhere else. According to information collected from farmers, accessions grown in each region are often used as table grapes and secondarily for the production of Arak (e.g. Hifawi in Jezzine, Merweh in North Lebanon, and sometimes for wine production (e.g. Marineh in Baalbek, Aassiri and Sweydeh in Bekaa).

Some accessions growing in different locations and having the same vernacular name, are classified differently in the dendrogram. This distribution into different groups of accessions supposedly belonging to the same variety, could be due to differences in agro-climatic conditions and cultural practices that normally influence the morphological characters [12]. Of course, homonyms and synonyms are not excluded in the case of the Lebanese vine germplasm, but they could be assessed only by a genetic analysis based on DNA markers [16]. A list of microsatellite markers are already developed to analyze genetic diversity in vine and identify autochthonous varieties $[14,17]$ and could be further used to analyze and differentiate the Lebanese varieties.

\section{Conclusion}

This study consisted of a survey and a characterization of 35 vine accessions grown in the main production regions in Lebanon (Bekaa, Baalbek-Hermel, North Lebanon, Mount Lebanon and South Lebanon), with the midterm perspective of evaluating the potential of vine genetic resources in the process of winemaking. Though 
preliminary, our findings show a significant morphological variability within the Lebanese germplasm of vine. Nevertheless, this morphological characterization should be further completed by a molecular analysis using DNA markers. Indeed, the genetic analysis of these resources will allow to determine the most likely genetic distances between accessions to make a choice of the diversity to conserve, differentiate the Lebanese varieties compared to the international germplasm, and consider their use in future breeding programs. Finally, new varieties identified during our study will normally be added to the national collection of LARI, which will present a scientific and patrimonial interest.

The authors are grateful to Mr Jean Luc Etievent from Wine Mosaic France for his kind support.

\section{References}

[1] D. Zohary. The origins and Ancient History of Wine (Mc Govern, P.E. et al., eds), 23-30 (1995)

[2] Ministry of Agriculture - FAO. Global Agricultural Census in Lebanon for 2010. pp 186 (2012)

[3] J.F. Roby. La filière viticole au Liban, analyse et propositions pour une évolution, 119 pp (2003)

[4] N. Rahal. Special report on wine tourism (2015) http://www. executive-magazine.com/ special-report/production-of-lebanesewine-is-on-a-slow-but-steady-growth-path

[5] http://www. lecommercedulevant.com/node/ 23400

[6] L. Chalak, S. Khalil, F. Kfoury, N. Madi, A. ElBitar, A. Chehade. Abstract and poster presentation and abstract. 21th LAAS International Science Conference, Beirut, Lebanon (2015)

[7] N. Madi. Thesis submitted in partial fulfillment of the requirements for the diploma of agricultural engineering from the Lebanese University (2007)

[8] FAO. Coping with climate change - the roles of genetic resources for food and agriculture. Rome, 110 pp (2015)

[9] OIV Descriptors list of grapevine varieties and vitis species. Paris, office international de la vigne et du vin (1983)

[10] G. Saporta, Editions Technip, Paris, 493p. (1990)

[11] Addinsoft. Xlstat for Excel, version 7. 5. Addinsoft, New York (2004)

[12] L. Chalak, H. Haouane, L. Essalouh, S. Santoni, G. Besnard and B. Khadari. Genet Resour Crop Evol 62 (4): 621-633 (2015)

[13] P. Galet, Dictionnaire Encyclopédique des Cépages. Hachette (2000)

[14] T. Lacombe, J.M. Boursiquot, V. Laucou, M. Di Vecchi-Staraz, J.P. Péros, P. This. Theor Appl Genet 126 (2), 401-14 (2013)

[15] F. Kfoury. Thesis submitted in partial fulfillment of the requirements for the diploma of agricultural engineering from the Lebanese University (2008)

[16] J.P. Roby, C. van Leeuwen, E. Gonçalves, A. Graça, and A. Martins. 37 World Congress of Vine and Wine, EDP Sciences 3 (2014)

[17] V. Laucou, T. Lacombe, F. Dechesne, R. Siret, J.P. Bruno, M. Dessup, T. Dessup,P. Ortigosa, P. Parra, C. Roux, S. Santoni, D. Varès, J.P. Péros, J.M. Boursiquot, P. This. Theor Appl Genet 122 (6):1233-45 (2011) 